\section{Aortobifemoral prosthesis penetrating the duodenal wall}

A 79-year-old woman with peripheral arterial disease affecting the abdominal aorta and the lower extremities underwent aortobifemoral bypass surgery in 2005. She was admitted 6 years later due to a massive hematemesis. An upper gastroin-

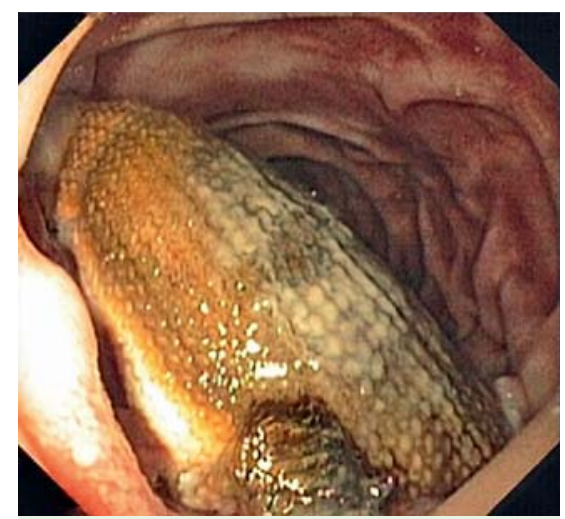

Fig. 1 View during an upper gastrointestinal endoscopy in a 79-year-old woman with peripheral arterial disease and hematemesis revealing penetration of the wall of the third part of the duodenum by an aortobifemoral prosthesis.

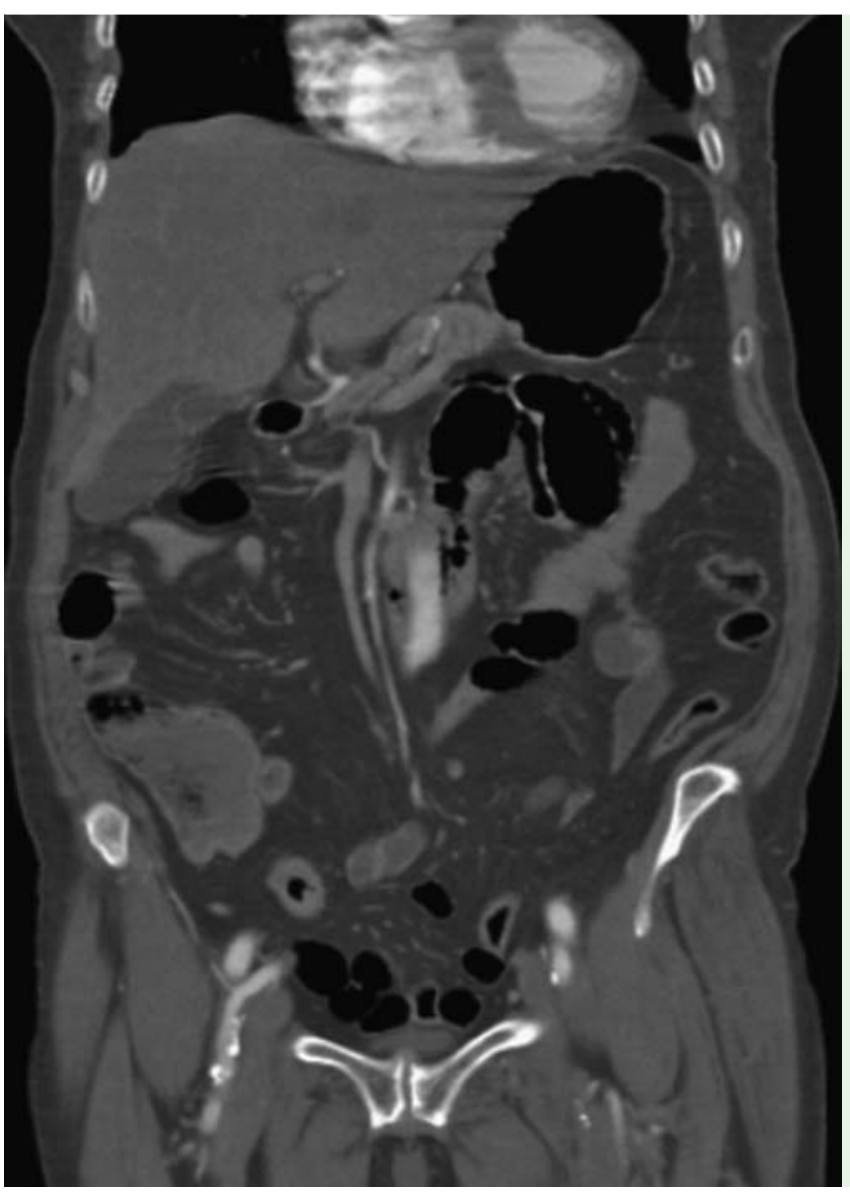

testinal endoscopy revealed a distended stomach filled with blood and a foreign body that was penetrating the wall of the third part of the duodenum and was identified as an aortobifemoral prosthesis ( Fig.1). An abdominal computed tomography (CT) scan was performed, which showed air in the duodenal wall and migration into the duodenum of an aortofemoral prosthesis ( $\bullet$ Fig. 2 ).

The patient underwent an axillofemoral bypass and duodenal enterectomy with removal of the aortobifemoral prosthesis. She survived and was discharged 30 days after surgery.

Aortoenteric fistulas can be primary, due to spontaneous formation of a communication between the lumen of an aortic aneurysm and an intestinal loop, or secondary following aortic surgery, caused by erosion of the aortic graft into the bowel $[1,2]$. Secondary aortoenteric fistulas complicate $0.36 \%-1.6 \%$ of aortic grafts, with $88 \%$ occurring in the third and fourth parts of the duodenum. The time between the first intervention and development of the fistula can vary from months to years $[1,2]$, the longest delay reported being more than 20 years [3]. Mechanical erosion of the prosthetic material into the adjacent bowel may be due to a lack of interposed retroperitoneal tissue, the excessive pulsation of redundantly placed grafts, or septic procedures [2].

The problem should be suspected when a patient with an aortobifemoral graft presents with upper gastrointestinal bleeding (most common), bowel obstruction, or unexplained fever [4]. Because of the high mortality and morbidity associated with secondary aortoenteric fistulas, surgical treatment is always recommended [2]. The best outcome is seen when an axillobifemoral reconstruction precedes removal of the aortic graft and closure of the stump [3].

\section{Endoscopy_UCTN_Code_CCL_1AB_2AZ_3AD}

\section{Competing interests: None}

\section{A. Albuquerque, G. Macedo}

Gastroenterology Department, Centro Hospitalar de São João, Porto, Portugal

\section{References}

1 La Greca G, Barbagallo F, Gagliardo S et al. Recurrent aortoduodenal fistula. Ann Vasc Surg 2011; 25: 386.e7-386.e11

computed tomography (CT) scan showing air in the duodenal wall and the aortofemoral prosthesis penetrating the third part of the duodenum.

2 Geraci G, Pisello F, Li Volsi F et al. Secondary aortoduodenal fistula. World J Gastroenterol 2008; 14: 484-486

3 Scheppach W, Polzien M, Kuesters W. Aortobifemoral prosthesis penetrating into the duodenal lumen. Clin Gastroenterol Hepatol 2011; 9: A28

4 Bergqvist D, Björck M. Secondary arterioenteric fistulation - a systematic literature analysis. Eur J Vasc Endovasc Surg 2009; 37: $31-42$

\title{
Bibliography
}

DoI http://dx.doi.org/

10.1055/s-0032-1325862

Endoscopy 2013; 45: E140

(c) Georg Thieme Verlag KG

Stuttgart · New York

ISSN 0013-726X

\section{Corresponding author}

\section{A. Albuquerque, MD}

Gastroenterology Department Centro Hospitalar de São João

Alameda Professor Hernâni Monteiro

4200-319 Porto

Portugal

Fax: +351-22-5025766

a.albuquerque.dias@gmail.com 